Rev. Inst. Flor . v. 26 n. 1 p. 43-53 2014

http://dx.doi.org/10.4322/rif.2014.003

ISSN impresso 0103-2674/on-line 2178-5031

\title{
VIVEIROS EDUCADORES COMO FERRAMENTA DE EDUCAÇÃO AMBIENTAL NO BRASIL E SUAS QUESTÕES JURÍDICAS ${ }^{1}$
}

\section{EDUCATIONAL PLANT NURSERIES AS A TOOL FOR ENVIRONMENTAL EDUCATION IN BRAZIL AND ITS LEGAL ISSUES}

\author{
André Gomes da ROCHA ${ }^{2,5}$; Paulo Henrique Peira RUFFINO; \\ Matheus Gonçalves dos REIS ${ }^{4}$
}

\begin{abstract}
RESUMO - A Educação Ambiental é uma ferramenta fundamental para o enfrentamento da crise socioambiental e tem valorizado, cada vez mais, os espaços pedagógicos que possibilitam o contato entre o ser humano e o meio natural, como os viveiros de mudas educadores. Estes, conquanto se destaquem como um bom instrumento em potencial para a promoção da educação ambiental, requerem uma análise sob a perspectiva de viabilidade e regularização jurídicas, demandando um estudo da legislação brasileira de sementes e mudas. Desse modo, o presente estudo buscou encontrar a inserção dos viveiros educadores nos marcos das bases legais que fundamentam a questão jurídica de mudas e sementes, e desenvolver um material de apoio para a criação de viveiros que estejam cientes de suas responsabilidades jurídicas. Por meio de: fundamentação teórica e conceitual de viveiros; da busca de informações junto a órgãos governamentais e a instituições relacionadas à produção de mudas; e de análise jurídica da legislação de sementes e mudas, foi possível concluir que a inviabilização de viveiros educadores por parte do Ministério de Agricultura, Pecuária e Abastecimento não deve ser encarada como inexorável, pois não há garantias de que esta categoria de viveiros deva ou não ser isenta das demandas burocráticas previstas na nova lei de sementes e mudas.
\end{abstract}

Palavras-chave: viveiro educador; lei de sementes; mudas florestais.

\begin{abstract}
The Environmental Education is a crucial tool to confront the social and environmental crises and the pedagogical places that allow contact between humans and the natural environment have been increasingly valued, such as the Educational Plant Nurseries. Even though they are good spots to promote environmental education, the viability to create a nursery depends on its juridical regularization, which requires a study of Brazilian legislation on seeds and seedlings. Thereby, the present study attempted to find the insertion of Educational Plant Nurseries in the Brazilian legislation and to develop a support material for the creation of nurseries that are aware of its legal responsibilities. Through: theoretical and conceptual review of nurseries; search for information from government bodies and institutions related on seedling production; and the legal analysis of the legislation on seeds and seedlings, it was possible to conclude that there is no legal justification for the unfeasibility of Educational Plant Nurseries because there is no guarantee that this category of plant nurseries should be or not be exempt from the bureaucratic demands contained in the new Brazilian seeds and seedlings laws.
\end{abstract}

Keywords: plant nursery; seeds legislation; seedling.

\footnotetext{
$\overline{1}$ Recebido para análise em 14.05.13. Aceito para publicação em 29.06.14.

${ }^{2}$ Universidade de São Paulo - USP, Escola de Engenharia de São Carlos, Av. Trabalhador São-Carlense, 400, 13566-590 São Carlos, SP, Brasil.

${ }^{3}$ Instituto Florestal, Rua do Horto, 931, 02377-000 São Paulo, SP, Brasil.

${ }^{4}$ Universidade Federal de São Carlos - UFSCar, Departamento de Ecologia e Biologia Evolutiva, Rod.Washington Luiz, km 235, 13565-905 São Carlos, SP, Brasil.

${ }^{5}$ Autor para correspondência: André Gomes da Rocha - andre.gomes.da.rocha@gmail.com
} 


\section{INTRODUÇÃO}

Viveiros florestais são locais que possuem a estrutura necessária para produção, manejo e proteção de mudas (Malheiros, 2005) até que estas tenham idade, tamanho e condições suficientes para resistir às adversidades reais de campo e obter um bom desenvolvimento (Paiva e Gomes, 2000). É, conforme Schmitt (2012), um local de passagem, onde as mudas são preparadas para melhor se adaptarem ao seu ambiente definitivo.

Um viveiro florestal pode desempenhar apenas a função de fábrica de mudas, sem possuir em seus processos uma reflexão dos mesmos (Lemos e Maranhão, 2008a). Em contrapartida, pode intencionalizar a reflexão sobre a forma como o ser humano tem se relacionado com o ambiente, trazendo aspectos e relações externas para dentro do processo de produção das mudas, isto é, pode ser um Viveiro Educador. A ideia de que a produção de mudas e o plantio de árvores são temas geradores bastante eficientes, por meio dos quais é possível estimular o entendimento sistêmico da questão ambiental, é relativamente nova e tem passado por adaptações, reformulações e aplicações práticas incipientes. Lemos e Maranhão (2008a), organizadores da cartilha "Viveiros Educadores: Plantando a Vida" lançada pelo Ministério do Meio Ambiente - MMA, optaram pela seguinte definição:

Viveiros educadores são espaços de produção de mudas vegetais onde, além de produzi-las, desenvolvem-se de forma intencional, processos que busquem ampliar as possibilidades de construção de conhecimento, exercitando em seus procedimentos e práticas, reflexões que tragam em seu bojo, o olhar crítico sobre questões relevantes para a Educação Ambiental como: ética, solidariedade, responsabilidade socioambiental, segurança alimentar, inclusão social, recuperação de áreas degradadas entre outras possibilidades. (Lemos e Maranhão, 2008a, p. 10).

Dessa maneira, fica clara a diferença entre o viveiro florestal convencional e o viveiro educador, ou seja, o espaço de aprendizagem, de formação pedagógica destinada aos que com ele interagem (Lemos e Maranhão, 2008a). Conectando essa ideia com a proposta de Pivelli e Kawasaki (2005) de aproximação do homem com o meio natural e aplicação de programas pedagógicos em espaços não formais, é possível então destacar os viveiros educadores como potenciais espaços importantes para a aplicação e difusão da educação ambiental.

No Brasil, a principal base legal que trata da legislação de viveiros é a Lei $n^{0} 10.711 / 2003$, que dispõe sobre o Sistema Nacional de Sementes e Mudas. O elo entre a implantação de viveiros educadores e suas bases legais é entendido como essencial para a construção da educação ambiental nestes espaços, sobretudo quando se constata que se tratam de elementos relativamente novos na área de produção de sementes e mudas no Brasil e que a Lei $\mathrm{n}^{\circ}$ 10.711/2003 ainda tem apresentado problemas de adequação em diversos setores devido à forma como foi concebida (Araújo, 2006).

Portanto, a questão apresentada no presente trabalho foi a tentativa de encontrar a inserção dos viveiros educadores nos marcos legais que fundamentam a questão jurídica de mudas e sementes, sobretudo de acordo com a Lei $\mathrm{n}^{\circ} 10.711 / 2003$, visto que diversas particularidades da lei ainda não foram adequadamente regulamentadas. O principal objetivo do trabalho foi fornecer um material de apoio sobre viveiros educadores no Brasil, particularmente sob o ponto de vista jurídico.

\subsection{Breve Revisão da Literatura}

\subsubsection{A problemática ambiental e a estratégia da educação}

Segundo Carvalho (2011), a sociedade atual passa notoriamente por uma crise ambiental pois, a partir da Revolução Industrial, os modos de produção e consumo tornaram-se tais, que têm superado a capacidade do sistema natural de prover recursos sustentavelmente. A mesma autora também destaca que isso advém, em grande parte, do distanciamento humano do meio natural, processo que se inicia com a ideia de natureza selvagem trazida pela modernidade cartesiana. 
ROCHA, A.G. da; RUFFINO, P.H.P.; REIS, M.G. dos. Viveiros educadores e suas questões jurídicas

Lemos e Maranhão (2008b) destacam que $o$ enfrentamento da crise socioambiental tem se tornado um desafio complexo, cercado por dificuldades ligadas a necessidades da sociedade moderna, e Frésca (2007) afirma que a crise tem se agravado com o aumento populacional, da urbanização e da transformação de hábitos de consumo.

Nesse contexto, evidencia-se a importância cada vez maior da educação ambiental, pois ela deve surgir como uma nova forma de encarar o papel do ser humano no mundo, intentando subverter a ordem vigente para propor, a partir de novos valores éticos, novos paradigmas e modelos de relações mais harmônicas com a natureza (São Paulo, 1999). No Brasil, a Política Nacional de Educação Ambiental - PNEA, instituída pela Lei ${ }^{\circ}$ 9.795/1999 afirma em seu Artigo $1^{\text {o }}$ :

Entende-se por educação ambiental os processos por meio dos quais o indivíduo e a coletividade constroem valores sociais, conhecimentos, habilidades, atitudes e competências voltadas para a conservação do meio ambiente, bem de uso comum do povo, essencial à sadia qualidade de vida e sua sustentabilidade. (Brasil, 1999).

Como enfatizam Pivelli e Kawasaki (2005), houve, ao longo dos últimos séculos, um distanciamento cada vez maior do ser humano com o mundo natural, e estabelecer um contato direto com a beleza e a diversidade pode ser uma estratégia eficaz de sensibilização e educação ambientais, despertando grandes potenciais pedagógicos nos espaços onde isso é possível, como são os casos, por exemplo, dos jardins botânicos, dos zoológicos e dos viveiros de mudas.

A importância da produção de mudas fica clara quando a conjuntura socioambiental atual é analisada e é fácil encontrar inúmeras referências do papel crucial que as árvores exercem no planeta. Para citar alguns exemplos: afora a óbvia utilização para reflorestamento, o plantio de árvores apresenta um papel importante no meio urbano e rural, porque além de terem uma função paisagística, as árvores auxiliam na melhoria da qualidade do meio ambiente e da vida humana (Rezende, 2011), como na redução dos níveis de poluição atmosférica, na melhoria do conforto térmico, no aumento da umidade relativa do ar, na ampliação da permeabilidade do solo, na conservação e preservação dos recursos hídricos e na estabilização das encostas (Lemos e Maranhão, 2008a).

Muito embora o plantio de árvores seja apenas uma das muitas frentes de atuação no processo de enfrentamento da ampla e sistêmica problemática socioambiental (Lemos e Maranhão, 2008b), Schmmit (2012) frisa que a arborização tem extrema importância na conservação da biodiversidade. Para Ruschel e Leite (2002) e Vargas (2007), o impacto ambiental originado pela expansão das cidades pode ser minorado por meio de um plano de arborização urbana. Dantas e Souza (2004) afirmam que a arborização contribui para o lado físico e mental do homem, e de acordo com Rossato et al. (2008), a arborização pode contribuir diretamente no aumento da qualidade de vida das pessoas que residem em áreas urbanizadas.

\subsubsection{Questões jurídicas e embasamento legal de viveiros de mudas}

A legislação concernente à produção de mudas e de sementes começou a surgir num contexto global em meados do século XX. Sob o pretexto de garantir aos agricultores o acesso a sementes e mudas de boa qualidade e assim aumentar a produtividade, essa tendência foi, na verdade, fruto da pressão de interesses comerciais de grandes empresas sementeiras dos Estados Unidos e da Europa, dentro do notório contexto da "Revolução Verde" das décadas de 1960 e 1970 (Londres, 2006).

Dentro do então cenário mundial, o Brasil se apresentou com um enorme potencial para a expansão das transnacionais e o desenvolvimento do agronegócio como temos hoje. Similarmente como ocorreu em outros países, os processos de reformulação da agropecuária brasileira pressionaram o poder público a criar leis para regularização das novas relações e processos econômicos relativos às questões do campo. 
Conforme Araújo (2006), no final do século passado e início deste, o setor agropecuário passou por notáveis transformações em suas normas reguladoras. Apesar de o início dessa transformação ter sido marcado pela edição da Lei Agrícola - Lei $\mathrm{n}^{\mathrm{o}}$ 8.171/1991-, foi a partir da edição da Lei de Patentes - Lei no 9.279/1996 que a mudança começou a ocorrer substancialmente, pois desde então foram criados mecanismos legais mais específicos para a regulamentação da produção de viveiros, mormente em aspectos presentes na Lei $\mathrm{n}^{\mathrm{o}}$ 9.456/1997, que trata da proteção de cultivares e na Lei $\mathrm{n}^{\mathrm{o}} 10.711 / 2003$, que institui o Sistema Nacional de Sementes e Mudas.
É possível dizer que essas mudanças vieram acompanhadas de uma conjuntura política econômica favorável ao crescimento da apropriação privada de produção vegetal, papel que o avanço do neoliberalismo econômico tipicamente tem exercido nas últimas décadas.

$\mathrm{Na}$ Tabela 1 constam, em ordem cronológica, os principais mecanismos legais que contribuíram para essa mudança.

O mesmo autor que as lista, afirma que uma análise política sobre o conteúdo dessas leis indica que há uma lógica, uma "espinha dorsal" que as conduz, sendo este foco voltado ao mercado, à menor participação estatal das atividades e à atenuação da rigidez das leis anteriores a estas.

Tabela 1. Principais mecanismos ao longo da história recente de mudanças na legislação de sementes e mudas no Brasil Table 1. Main mechanisms throughout recent history of changes in legislation on seeds and seedlings in Brazil.

\begin{tabular}{|c|c|}
\hline Ano & Diploma Legal \\
\hline 1995 & Lei $\mathrm{n}^{\circ} 8.974$ - Normas para uso de engenharia genética \\
\hline 1996 & Lei $n^{\circ} 9.279$ - Lei da Propriedade Industrial \\
\hline 1997 & Lei $n^{\circ} 9.456$ - Lei de Proteção de Cultivares \\
\hline 2000 & Lei n ${ }^{\circ} 9.972$ - Institui a Classificação de produtos vegetais, subprodutos e resíduos \\
\hline 2000 & Lei $\mathrm{n}^{\circ} 9.973$ - Dispõe sobre o sistema de armazenagem dos produtos agropecuários \\
\hline 2003 & Lei $\mathrm{n}^{\circ} 10.711$ - Dispõe sobre o Sistema Nacional de Sementes e Mudas \\
\hline 2004 & Decreto $^{\circ} 5.153$ - Regulamenta a Lei $n^{\circ} 10.711 / 2003$ \\
\hline 2005 & Lei $n^{\circ} 11.105$ - Lei de Biossegurança \\
\hline 2007 & Decreto $n^{\circ} 6.041$ - Institui a Política de Desenvolvimento da Biotecnologia \\
\hline 2010 & Lei $\mathrm{n}^{\circ} 12.341$ - Define prioridades para a destinação de produtos de origem vegetal \\
\hline 2011 & $\begin{array}{l}\text { Instrução Normativa } n^{\circ} 56 \text { - Traz as normas para produção, comercialização e utilização de mudas e } \\
\text { sementes, considerando o disposto na Lei } n^{\circ} 10.711 / 2003\end{array}$ \\
\hline 2012 & Decreto n 7.794 - Institui a Política Nacional de Agroecologia e Produção Orgânica \\
\hline 2012 & Lei $\mathrm{n}^{\circ} 12.651$ - Novo Código Florestal \\
\hline
\end{tabular}

Fonte: Araújo (2006, p. 7), adaptada pelos autores do presente trabalho. 


\section{MATERIAL E MÉTODOS}

O material de apoio baseia-se fundamentalmente na revisão bibliográfica de viveiros educadores e suas correspondências na legislação brasileira. A metodologia se deu por duas frentes:

a) viveiros educadores e o cenário brasileiro: fundamentação teórica e conceitual sobre viveiros educadores por meio de pesquisas bibliográficas relacionadas à temática;

b) legislação aplicada a viveiros educadores:

pesquisa bibliográfica para fundamentação jurídica da legislação de sementes e mudas no país, sobretudo:

- a Lei $\mathrm{n}^{\mathrm{o}} 10.711 / 2003$, que institui o Sistema Nacional de Sementes e Mudas;

- a regulamentação da Lei $\mathrm{n}^{0}$ 10.711/2003, aprovada pelo Decreto $n^{\circ}$ 5.153/2004;

- a Instrução Normativa - IN no 56/2011, que traz as normas para produção, comercialização e utilização de mudas e sementes, considerando o disposto na Lei $\mathrm{n}^{\circ}$ 10.711/2003;

contato - via correspondência eletrônica com as instituições governamentais responsáveis pela aplicação da legislação de sementes e mudas no país: o Ministério da Agricultura, Pecuária e Abastecimento MAPA e o Ministério do Meio Ambiente MMA. O contato com o MAPA se deu por meio da Superintendência Federal de Agricultura no Estado de São Paulo - SFA-SP e do Serviço de Fiscalização de Insumos Agrícolas - SEFIA, da Divisão de Defesa Agropecuária da SFA-SP, com sede na cidade de Campinas. O contato com o MMA se deu por meio da Ouvidoria do Ministério;

intercâmbio de informações, via correspondência eletrônica, com outros viveiros para reconhecimento da conjuntura jurídica e educacional em que estão inseridos. Dos viveiros contatados, dois foram selecionados por apresentarem respostas mais completas e perfis distintos entre si.

\section{RESULTADOS E DISCUSSÃO}

Os resultados alcançados foram categorizados em quatro frentes que se dividem de acordo com as etapas do processo de pesquisa. As duas primeiras trazem as resoluções da pesquisa bibliográfica no âmbito jurídico da produção de mudas e sementes, sob a conjuntura do viveiro educador. As duas últimas apresentam os resultados das informações trocadas com outros agentes do processo, como os órgãos governamentais e os viveiros educadores.

\subsection{O Sistema Nacional de Sementes e Mudas}

A Lei $n^{0} 10.711 / 2003$, regulamentada pelo Decreto $\mathrm{n}^{\mathrm{o}} 5.153 / 2004$ e normatizada pela instrução $n^{0}$ 56/2011, veio substituir e revogar a antiga Lei de Sementes - Lei $n^{\circ}$ 6.507/1977. Segundo Araújo (2006), trata-se de aspiração antiga dos setores produtores de sementes e empresas envolvidas em pesquisa e desenvolvimento de novas cultivares

A Lei $\mathrm{n}^{0} 10.711 / 2003$ dispõe sobre o Sistema Nacional de Sementes e Mudas - SNSM, o qual "objetiva garantir a identidade e a qualidade do material de multiplicação e de reprodução vegetal produzido, comercializado e utilizado em todo o território nacional" (Brasil, 2003). O SNSM compreende diversas atividades, desde o registro de sementes e mudas até sua certificação, utilização, fiscalização da produção, do beneficiamento, da amostragem, da análise, do armazenamento, do transporte e da comercialização, instituindo o Registro Nacional de Sementes e Mudas RENASEM e o Registro Nacional de Cultivares RNC. Em seu artigo $8^{\circ}$, a Lei exige que:

As pessoas físicas e jurídicas
que exerçam as atividades de
produção, beneficiamento, embalagem,
armazenamento, análise, comércio,
importação e exportação de sementes
e mudas ficam obrigadas à inscrição no
RENASEM. (Brasil, 2003).

Da mesma forma, em seus artigos 10 e 11, a lei institui o RNC e exige que a produção, o beneficiamento e a comercialização de sementes e mudas fiquem condicionados à prévia inscrição da respectiva cultivar, sendo esta definida como: 
A variedade de qualquer gênero ou espécie vegetal superior que seja claramente distinguível de outras cultivares conhecidas, por margem mínima de descritores, por sua denominação própria, que seja homogênea e estável quanto aos descritores através de gerações sucessivas e seja de espécie passível de uso pelo complexo agroflorestal, descrita em publicação especializada disponível e acessível ao público, bem como a linhagem componente de híbridos. (Brasil, 2003).

Londres (2006) mostra que as regras determinadas por essa nova Lei de Sementes introduziram aspectos que a tornam vinculada à Lei de Proteção de Cultivares - Lei no 9.456/1997 -, a qual deu origem, no universo jurídico brasileiro, à propriedade intelectual no campo vegetal. Desse modo, reforçam-se os direitos exclusivos de produção venda das sementes protegidas e recebimento de royalties pelas concessões de uso destes materiais. Observa-se que muito mais do que proteger os agricultores com relação à qualidade das sementes utilizadas, as leis de propriedade vegetal objetivam garantir o controle de mercado às grandes empresas (Londres, 2006).

\subsection{A Lei de Sementes e o Viveiro Educador}

O Sistema Nacional de Sementes e Mudas claramente se propõe a tratar dos casos mais gerais e comuns de uso vegetal. Como mostrado, possui uma fundamentação teórica, científica, técnica, econômica e política que desenha a Lei a ser aplicada para grandes produtores e comerciantes de mudas e sementes. Prova disso são as diversas ressalvas que constam no corpo da Lei ao isentar alguns grupos de determinadas atribuições. Toma-se como exemplo didático o parágrafo $3^{\circ}$ do Artigo $8^{\circ}$ da Lei $n^{\circ} 10.711 / 2003$ :

Ficam isentos da inscrição no RENASEM os agricultores familiares, os assentados da reforma agrária e os indígenas que multipliquem sementes ou mudas para distribuição, troca ou comercialização entre si. (Brasil, 2003).

Para Londres (2006), essas exceções decorrem, em grande parte, da luta política que osegmentos vinculados às categorias interessadas empreenderam ao longo da elaboração da Lei.
Também faz parte desse processo, por exemplo, o reconhecimento da semente crioula ou, em outras palavras, a variedade desenvolvida, adaptada ou produzida tradicionalmente e reconhecida pelas comunidades de agricultores familiares, assentados ou indígenas.

Ainda que a nova lei apresente esses elementos contra-hegemônicos, Londres (2006) nos dá exemplos de como ela trata, majoritariamente, da agricultura dominante latifundiária, favorecendo o status quo do setor primário brasileiro. A autora cita, por exemplo, o caso de pequenos comércios informais e processos de troca de sementes e mudas de agricultores familiares que têm sido prejudicados pela atuação das secretarias estaduais quando estas dizem estar cumprindo a Lei, e alerta que isto acontece porque a legislação não se propõe a tratar os casos específicos e exceções resultantes de suas determinações, isto é, simplesmente os cita no corpo da Lei.

Surge uma questão, portanto. Que parte da lei contempla os viveiros ditos informais ou que produzam mudas e sementes para outros fins que não comerciais, tais como educação ambiental ou pesquisa? Destarte, a regulamentação da Lei ${ }^{\circ}$ 10.711/2003, aprovada pelo Decreto $n^{\circ} 5.153 / 2004$, foi considerada de grande relevância na abordagem da questão proposta, de modo que um estudo pormenorizado e específico da mesma foi necessário para melhor compreensão e discussão do tema.

Dentro do Decreto, pode-se destacar o artigo mais importante para o caso em estudo. Presente no capítulo "XII - Das Espécies Florestais, Nativas ou Exóticas, e das de Interesse Medicinal ou Ambiental", na "Seção V - Do Processo de Produção e Certificação", o artigo 175 deixa claro onde a inserção de um viveiro educador se dá na legislação:

Ficam dispensadas das exigências de inscrição no RENASEM instituições governamentais ou não-governamentais que produzam, distribuam ou utilizem sementes e mudas de que trata este Capítulo, com a finalidade de recomposição ou recuperação de áreas de interesse ambiental, no âmbito de programas de educação ou conscientização ambiental assistidos pelo poder público. Parágrafo único. As atividades de produção, distribuição ou utilização de sementes e mudas de que trata o caput devem estar descaracterizadas de qualquer fim ou interesse comercial. (Brasil, 2004). 
Depois de analisada toda a regulamentação da Lei, a principal conclusão é a de que, tal como descreve o artigo 175, um viveiro educador, assim como quaisquer viveiros sem fins comerciais, estariam isentos de inscrição no RENASEM. Para confirmar isso, foi analisada a Instrução Normativa - IN n ${ }^{\circ} 56 / 2011$, que traz as normas para produção, comercialização e utilização de mudas e sementes, considerando o disposto na Lei $\mathrm{n}^{\mathrm{o}}$ 10.711/2003.

Corroborando o art. 175 do Decreto, o artigo 54 da IN declara:

Art. 54. As instituições governamentais ou não-governamentais que produzam, distribuam ou utilizem sementes e mudas das espécies florestais com a finalidade de recomposição ou recuperação de áreas de interesse ambiental, no âmbito de programas de educação ou conscientização ambiental assistidos pelo poder público, ficam dispensadas das exigências de inscrição no RENASEM, conforme previsto no art. 175 do Anexo do Decreto $\mathrm{n}^{\circ}$ 5.153, de 23 de julho de 2004, hipótese em que deverão apresentar declaração, antes do início da produção, ao órgão de fiscalização da Unidade da Federação onde se realizará a produção do material de propagação, nos termos do Anexo XIV desta Instrução Normativa. Parágrafo único. Os responsáveis pela declaração deverão encaminhar o Relatório de Utilização de Sementes e Mudas de que trata o art. 175 do Anexo do Decreto ${ }^{\circ}$ 5.153, de 2004, ao órgão de fiscalização da Unidade da Federação, onde se realizou a produção do material de propagação, até 30 (trinta) de março do ano subsequente, conforme o Anexo XV desta Instrução Normativa. (Brasil, 2011).

Dessa forma, fica claro que para a regularização legal de um viveiro educador é necessário apresentar a Declaração de Produção de Sementes e Mudas de que trata o art. 175 e seu respectivo relatório anual.

\subsubsection{Informações institucionais}

A correspondência eletrônica com o Ministério da Agricultura, Pecuária e Abastecimento MAPA a fim de maiores esclarecimentos em relação à Declaração de Produção de Sementes e Mudas foi respondida por uma Engenheira Agrônoma, Fiscal Federal Agropecuária pela Fiscalização de Sementes e Mudas - FISCALSEM do SEFIA - Unidade Técnica Regional de Agricultura, Pecuária e Abastecimento em Campinas.

Segundo a Engenheira, a orientação da nova legislação, por meio do artigo 175 da Lei $n^{\circ}$ 10.711/2003, é que apenas os programas educacionais assistidos pelo poder público estão isentos de inscrição no RENASEM. A fiscal enalteceu que programas assistidos pelo poder público devem, obrigatoriamente, ser oficializados por meio de publicação em Diário Oficial do estado ou município, informando a verba envolvida, sua procedência orçamentária e o uso dessa verba com base contratual, assim como as entidades elencadas e a descrição de suas atribuições. A fiscal orientou, ainda, que a isenção não se aplica a compromissos entre associações, programas internos de fundações ou de ONGs, ou ainda a viveiros de Unidades de Conservação, mesmo que de propósito de produção interno, como foi o caso da pesquisa que originou este trabalho.

A resposta da Engenheira levantou, então, alguns questionamentos centrais para o estudo em questão. A nova legislação não contempla aqueles viveiros que não possuem caráter comercial, ou seja, não têm fins lucrativos e que, ao mesmo tempo, não sejam "assistidos pelo poder público"? $\mathrm{O}$ que o texto da Lei quer dizer com os programas que são assistidos pelo poder público, isto é, quais as exigências e atribuições contempladas com esse termo? Segundo Londres (2006), durante a realização de um estudo no mesmo ano, nenhum dos funcionários do Ministério da Agricultura, Pecuária e Desenvolvimento - MAPA entrevistados foi capaz de responder com precisão o que se entende por "assistidos pelo poder público".

Causou estranheza o fato de o Ministério do Meio Ambiente - MMA ter lançado o programa "Viveiros Educadores: Plantando a Vida", organizado por Lemos e Maranhão (2008a), no ano, e não o ter relacionado com a legislação de sementes e mudas. Por meio da ouvidoria do Ministério, a bióloga responsável afirmou que à época do lançamento da cartilha, o objetivo era o de estimular, orientar e apoiar a implementação de viveiros florestais como espaço de aprendizagem, independentemente do caráter comercial ou não do viveiro. 
Conforme informações da bióloga, um dos desdobramentos concretos foi a contribuição conceitual do projeto para a implantação dos Centros de Referência para Recuperação de Áreas Degradadas - CRADs, que visam à recuperação de áreas degradadas com projetos ligados a cursos de capacitação para formação de recursos humanos, com procedimentos de coletas de semente, produção de mudas, plantio e tratos silviculturais, ações bem próximas ao que o projeto "Viveiros Educadores: Plantando a Vida" se propunha. A Tabela 2 lista os sete CRADs que foram criados, todos na Bacia Hidrográfica do São Francisco.

Ainda, após ser indagada sobre o impasse legal levantado por este estudo, a bióloga disse que o MMA não tem condições de esclarecer sobre o que a lei determina por se tratar de atributo longínquo da seara daquele Ministério.

Tabela 2. Centros de Referência para Recuperação de Áreas Degradadas.

Table 2. Reference Centers for Rehabilitation of Degraded Lands.

\begin{tabular}{lll}
\hline CRAD & Localização & Universidade \\
\hline Alto São Francisco & Arcos - MG & Universidade Federal de Lavras - UFLA \\
\hline UnB & Brasília - DF & Universidade de Brasília \\
Caatinga & Petrolina - PE & Universidade Federal do Vale do São Francisco - UNIVASF \\
Baixo São Francisco & $\begin{array}{l}\text { Arapiraca }- \text { AL } \\
\text { Propriá - SE }\end{array}$ & Universidade Federal de Alagoas - UFAL \\
\hline Cerrado Baiano & Barreiras - BA & Universidade Federal da Bahia \\
Serra Talhada & Serra Talhada - PE & Universidade Federal Rural de Pernambuco - UFRPE \\
Mata Seca & Janaúba - MG & Universidade Estadual de Montes Claros - Unimontes \\
\hline
\end{tabular}

\subsection{Outros Viveiros Educadores}

Dos viveiros educadores contatados, dois merecem destaque. Um está localizado em Itapuã do Oeste - RO e outro em Pilar do Sul - SP.

O primeiro é um viveiro do Centro de Estudos da Cultura e do Meio Ambiente da Amazônia Rioterra, uma Organização da Sociedade Civil de Interesse Público - OSCIP criada em 1999 com sede em Porto Velho - RO. Segundo a coordenação do Centro, o seu viveiro educador é municipal e destina-se a doar mudas para trabalhos de educação, recuperação de áreas etc. Quando foi dada a entrada no Ministério da Agricultura, Pecuária e Abastecimento - MAPA para obtenção do RENASEM, o próprio MAPA passou a legislação que os isenta do mesmo e orientou sobre o que fazer para finalizar o processo.
Foi dito que em nenhum dos contatos com o Ministério foi citada a questão de publicação em Diário Oficial, ressaltando que a Lei é clara e nada fala sobre isto. Ainda em tempo, o representante do viveiro em questão opinou que as informações do MAPA repassadas ao primeiro autor do presente artigo devem se tratar de uma desinformação da fiscal da SAF, pois aquele viveiro já foi até fiscalizado e nunca houve problemas com a ausência de RENASEM.

$O$ segundo caso trata de um viveiro educador do Instituto Refloresta, localizado no município de Pilar do Sul - SP, onde se encontra um dos cinco núcleos do Instituto. Segundo a coordenação do Instituto, o RENASEM é um registro importante e necessário para eles, pois têm uma produção significativa que atende tanto aos seus projetos, quanto à comercialização, apesar de nunca terem sido fiscalizados. 
Declararam, ainda, que percebem que o MAPA ainda não está totalmente seguro e uniforme em relação à aplicação da norma, o que leva a acreditar que a exigência da fiscal da SAF deva ser um ponto de vista particular. Eles acreditam que a IN $n^{\circ} 56 / 2011$ ainda vai gerar polêmicas, principalmente no caso da produção de sementes, em que simplesmente existem exigências, segundo os mesmos, impossíveis de serem cumpridas no atual momento.

\section{CONCLUSÕES}

O estudo possibilitou uma visão geral da conjuntura da chamada nova legislação de sementes e mudas e sua aplicação em viveiros educadores. A análise das bases legais e seu vínculo com os viveiros educadores foram encarados como processos de grande importância para tentar estabelecer este material de apoio à viabilização jurídica de viveiros.

Conforme o estudo da legislação e os contatos estabelecidos com pessoas físicas e jurídicas que de alguma forma têm se situado em relação ao conceito de viveiros educadores e aos preceitos da legislação, não foi possível encontrar justificativa legal para a inviabilização de viveiros educadores que sejam isentos de inscrição no Registro Nacional de Sementes e Mudas - RENASEM e no Registro Nacional de Cultivares - RNC. Embora o contato com a Superintendência do Ministério da Agricultura, Pecuária e Desenvolvimento - MAPA no Estado de São Paulo ter aparentemente mostrado que os casos de que trata o artigo 175 da Lei $n^{\circ} 10711 / 2003$ são apenas os que estiverem assistidos pelo poder público, não foi possível definir exatamente o que este termo permite ou exclui, devido às diversas informações divergentes recebidas de outras fontes. Estas, inclusive, mostraram casos e exemplos em que viveiros educadores estão consolidados e em funcionamento pleno.

Um ponto que merece ser enfatizado é o fato de o Ministério do Meio Ambiente não ter se preocupado ou citado as particularidades jurídicas dos viveiros educadores à época da publicação do trabalho "Viveiros Educadores: Plantando a Vida". Além disso, não houve um monitoramento adequado dos desdobramentos e resultados da publicação, com alguns poucos casos citados por eles, como os CRADs que, na verdade, simplesmente se apropriaram de alguns conceitos presentes no trabalho anterior, e não necessariamente têm aplicado educação ambiental em viveiros.

Ademais, percebe-se que a Lei $n^{\circ}$ 10.711/2003 e suas regulamentações têm gerado muita polêmica por apresentarem pequenos interstícios e elementos extremamente difíceis de serem aplicados. É o caso dos viveiros educadores que não possuem fins comerciais e que, dessa modo, não geram evidências de que seja necessária a adequação às burocracias demandadas por viveiros florestais convencionais, como o registro no RENASEM. Observa-se que a burocracia imposta a esses tipos de viveiros educadores não apenas não auxilia no processo de produção de mudas e sementes, mas também prejudica o desenvolvimento da educação ambiental do país, visto que inviabiliza a existência de tais espaços. A impressão que se tem, é que, conforme alertado por Londres (2006) e Araújo (2006), a Lei ${ }^{\circ} 10.711 / 2003$ se enquadra no conjunto de medidas tomadas em favor de garantir o mercado às grandes empresas da produção de mudas e sementes, em detrimento de pequenas iniciativas e casos particulares que não são tratados de forma completa no escopo da Lei.

Por fim, sugere-se a continuidade do estudo e do debate acerca da legislação de mudas e sementes aplicada a viveiros educadores, com vistas à sua não inviabilização ao mesmo passo que se tenha sua adequação legal frente às suas demandas jurídicas, fato importante para evitar a impossibilidade de consolidação de importantes espaços de educação ambiental que são os viveiros educadores.

\section{AGRADECIMENTOS}

Ao Conselho Nacional de Desenvolvimento Científico e Tecnológico - CNPq e ao Instituto Florestal - IF que, junto ao Programa Institucional de Bolsas de Iniciação Científica - PIBIC/IF financiaram a "Pesquisa e Práticas em Educação Ambiental no Viveiro Educador Jatobá, Estação Experimental de Itirapina", desenvolvida entre 2012 e 2013 e que propiciou o aprofundamento específico das questões jurídicas dos viveiros educadores aqui publicadas. 


\section{REFERÊNCIAS BIBLIOGRÁFICAS}

ARAÚJO. J.C. Algumas observações sobre a legislação de sementes e mudas. In: LONDRES, F. A nova legislação de sementes e mudas no Brasil e seus impactos sobre a agricultura familiar. Rio de Janeiro: Articulação Nacional de Agroecologia, 2006. p. 7-12. Disponível em: $<$ http://www.redsemillas.info/wp-content/ uploads/2007/02/legislacao-sementes-e-mudas_ br.pdf $>$. Acesso em: maio 2013.

BRASIL. Lei n ${ }^{\circ}$ 9.795, de 27 de abril de 1999. Dispõe sobre a educação ambiental, institui a Política Nacional de Educação Ambiental e dá outras providências. Disponível em: <http://www. planalto.gov.br/ccivil_03/leis/19795.htm>. Acesso em: maio 2013.

BRASIL. Lei $\mathrm{n}^{\mathrm{o}} 10.711$, de 5 de agosto de 2003. Dispõe sobre o Sistema Nacional de Sementes e Mudas e dá outras providências. Disponível em: $<$ http://www.planalto.gov.br/ccivil 03/leis/2003/110.711.htm>. Acesso em: jun. 2013.

BRASIL. Decreto $\mathrm{n}^{\circ} 5.153$, de 23 de julho de 2004. Aprova o Regulamento da Lei $n^{\circ} 10.711$, de 5 de agosto de 2003, que dispõe sobre o Sistema Nacional de Sementes e Mudas - SNSM, e dá outras providências. Disponível em: $<$ http://www.planalto.gov.br/ccivil_03/_ato20042006/2004/decreto/d5153.htm>. Acesso em: maio 2013.

BRASIL. Instrução Normativa $\mathrm{n}^{\circ}$ 56, de 8 de dezembro de 2011. Traz as normas para produção, comercialização e utilização de mudas e sementes, considerando o disposto na Lei $n^{\circ}$ 10.711 de 5 de agosto de 2003. Disponível em: $<$ http://www.adagri.ce.gov.br/Docs/legislacao_vegetal/ IN_56_de_08.12.2011.pdf $>$. Acesso em: jun. 2013.

CARVALHO, I.C.M. Uma história social das relações com a natureza. In: Educação ambiental: a formação do sujeito ecológico. 2. ed. São Paulo: Cortez, 2011. cap. 5, p. 89-108.

DANTAS, I.C.; SOUZA, C.M.C. Arborização urbana na cidade de Campina Grande - PB: inventário e suas espécies. Revista de Biologia e Ciências da Terra, v. 4, n. 2, 2004. Disponível em: $<$ http://eduep.uepb.edu.br/rbct/sumarios/pdf/ arborizaurbana.pdf $>$. Acesso em: jun. 2013.
FRÉSCA, F.R.C. Estudo da geração de resíduos sólidos domiciliares no Município de São Carlos, SP, a partir da caracterização física. 2007. 133 f. Dissertação (Mestrado em Ciências da Engenharia Ambiental) - Escola de Engenharia de São Carlos, Universidade de São Paulo, São Carlos.

LEMOS, G.N.; MARANHÃO, R.R. Viveiros educadores: plantando a vida. Brasília, DF: MMA, 2008a. 84 p.

Educador como espaço para a Educação Ambiental. Ambientalmente Sustentable, v. 2, n. 6, p. 173-190, 2008b.

LONDRES, F. A nova legislação de sementes e mudas no Brasil e seus impactos sobre a agricultura familiar. Rio de Janeiro: Articulação Nacional de Agroecologia, 2006. 37 p. Disponível em: $<$ http://www.redsemillas.info/wp-content/ uploads/2007/02/legislacao-sementes-e-mudas br.pdf $>$. Acesso em: junho 2013.

MALHEIROS, R. Montagem e operacionalização de viveiro convencional para produção de mudas. Goiânia: Pontifícia Universidade Católica de Goiás, Instituto do Trópico Subúmido, 2005. 12 p. Disponível em: <http://www.pucgoias.edu.br/ ucg/eventos/SemanaCulturaCidadania/ SetimaSemana/ArquivosUpload/1/file/7\%20 Semana/projeto\%20montagem\%20de\%20viveiro. pdf $>$. Acesso em: junho 2013.

PAIVA, H.N.; GOMES, J.M. Viveiros florestais. 2. ed. Viçosa, MG: Universidade Federal de Viçosa, 2000. 69 p. (Cadernos Didáticos, 72).

PIVELLI, S.R.P.; KAWASAKI, C.S. Análise do potencial pedagógico de espaços não-formais de ensino para o desenvolvimento da temática da biodiversidade e sua conservação. In: ENCONTRO NACIONAL DE PESQUISA EM EDUCAÇÃO EM CIÊNCIAS, 5., 2005, Bauru. Anais... Bauru: ABRAPEC, nov./dez. 2005. Disponível em: $<$ http://www.nutes.ufrj.br/abrapec/venpec/conteudo/ $\operatorname{artigos/1/pdf/p674.pdf>}$. Acesso em: jun. 2013.

REZENDE, R.R. Viveiros Educativos: construindo uma nova realidade a partir da educação ambiental popular em um contexto socioambiental. Fórum Ambiental da Alta Paulista, v. 7, n. 6, não paginado, 2011. 
ROCHA, A.G. da; RUFFINO, P.H.P.; REIS, M.G. dos. Viveiros educadores e suas questões jurídicas

ROSSATO, D.R.; TSUBOY, M.S.F.; FREI, F. Arborização urbana na cidade de Assis-SP: uma abordagem quantitativa. Rev. SBAU, v. 3, n. 3, p.1-16, 2008.

RUSCHEL, D.; LEITE, S.L.C. Arborização urbana em uma área da cidade de Lajeado, Rio Grande do Sul, Brasil. Caderno de Pesquisa Ser. Bio, v. 14, n. 1, p. 7-24, 2002.

SÃO PAULO (Estado). Secretaria do Meio Ambiente. Conceitos para se fazer educação ambiental. 3. ed. São Paulo, 1999. 48 p.

SCHMITT. L.A. Implantação de um viveiro de mudas educador no campus central da Pontifícia Universidade Católica do Rio Grande do Sul. 2012. 37 f. Trabalho de conclusão de curso de graduação (Ciências Biológicas) - Faculdade de Biociências, Pontifícia Universidade Católica do Rio Grande do Sul, Porto Alegre.

VARGAS, E.T. Um viveiro de mudas como ferramenta para o ensino de ecologia, botânica e educação ambiental. 2007. 102 f. Dissertação (Mestrado em Ensino de Ciências e Matemática) Pontifícia Universidade Católica, Belo Horizonte. 